\title{
Influence of Methodological Variables on Fracture Strength Tests Results of Premolars with Different Number of Residual Walls. A Systematic Review with Meta-Analysis
}

\author{
Carlo Gaeta *(D), Crystal Marruganti (D), Emanuele Mignosa, Giovanni Franciosi, Edoardo Ferrari \\ and Simone Grandini
}

check for updates

Citation: Gaeta, C.; Marruganti, C.; Mignosa, E.; Franciosi, G.; Ferrari, E.; Grandini, S. Influence of

Methodological Variables on Fracture Strength Tests Results of Premolars with Different Number of Residual Walls. A Systematic Review with Meta-Analysis. Dent. J. 2021, 9, 146. https://doi.org/10.3390/dj9120146

Academic Editor: Luca Giachetti

Received: 24 October 2021

Accepted: 18 November 2021

Published: 2 December 2021

Publisher's Note: MDPI stays neutral with regard to jurisdictional claims in published maps and institutional affiliations.

Copyright: (c) 2021 by the authors. Licensee MDPI, Basel, Switzerland. This article is an open access article distributed under the terms and conditions of the Creative Commons Attribution (CC BY) license (https:/ / creativecommons.org/licenses/by/ $4.0 /)$.
Unit of Endodontics and Restorative Dentistry, Department of Medical Biotechnologies, University of Siena, 53100 Siena, Italy; marruganti@gmail.com (C.M.); emanuele-mignosa@outlook.it (E.M.); giofrancio@libero.it (G.F.); edoardo.ferrari.cagidiaco@gmail.com (E.F.); grandini@unisi.it (S.G.)

* Correspondence: c.gaeta@student.unisi.it

Abstract: The aim of the current meta-analysis was to assess the impact of methodological variables in performing fracture strength tests of upper premolars. Medline (Pubmed), Embase and Google Scholar were screened for studies performing ex vivo fracture strength tests of intact upper premolars or premolars with 0,1 or 2 walls lost. The outcome variable for each study was the maximum breaking load expressed in Newton $\left(\mathrm{kg} \times \mathrm{m} / \mathrm{s}^{2}\right)$. Methodological variables (i.e., simulation of the periodontal ligament, load inclination, tip position, tip diameter and thermocycling) were registered to perform subgroup analyses and meta-regression. Overall, 25 studies and 78 study groups were included in the meta-analysis. Intact premolars (17 study groups) were not significantly influenced by any of the methodological variables considered. Subgroup analysis for load inclination $\left(30^{\circ} / 45^{\circ}\right.$ vs. $90^{\circ} / 150^{\circ}$ ) was significant for premolars with 0 (10 study groups), 1 (6 study groups) and 2 (45 study groups) walls lost; thermocycling was significant for premolars with 1 and 2 walls lost. A strong methodological heterogeneity across studies evaluating the fracture strength of upper premolars was highlighted, especially when 0,1 or 2 walls were lost. Further studies are needed to standardize the methodology used in order to allow for across-studies comparisons.

Keywords: fracture strength test; endodontically treated teeth; premolar

\section{Introduction}

Restorative procedures and Endodontic treatment produce extensive loss of dentine structure favoring risk of fracture and tooth loss [1,2]. It is widely accepted that the extension of access cavity during endodontic treatment and consequently the number of walls lost as well as the removal of occlusal marginal ridges could sensibly affect the strength of the teeth involved [3]. Upper premolars are more prone to fracture compared to molars because of their position in the mouth and the anatomical features, such as the shape, crown volume and crown/root proportion [4]. Fracture strength test remains a common experimental method to evaluate the restorative procedure for root filled teeth despite shortcomings being highlighted regarding the correct physiological load, the teeth used in the experiment, and the differences in test conditions [5]. The pattern of loading plays a crucial role in the fracture strength test, in which it tends to simulate the occlusal forces in the mouth. The direction and location of the loading tip as well as the shape and the diameter may influence the results of the test. Usually, the direction of the applied forces, used in this in vitro test, are axial on both buccal and palatal cusps with an inclination of $30 / 45^{\circ}$, and this could sensibly influence the outcome of the test [6]. The periodontal ligament is an anatomical structure able to distribute the occlusal load thanks to its fibers. Its inclusion in the fracture strength test is confirmed by a finite element analysis study [7] and it seems to influence the results of the in vitro test [8]. Thermo 
cycling is an in vitro procedure used to simulate the thermal stresses that usually occur during masticatory function [9]. This tooth aging treatment seems to considerably affect the results, if applied [10]. To date, no systematic review or meta-analysis is present regarding the impact of methodological variables related to the experiment on the fracture strength of the teeth evaluated. Such results may have an implication regarding the testing phase of different restorative materials, and could also serve as a guide for future studies. The aim of the present systematic review is to evaluate the influence of methodological variables such as Thermocycling, Periodontal ligament simulation, Load inclination and Tip diameter, on fracture strength test of upper premolar with intact, $0,1,2$ walls lost.

\section{Materials and Methods}

\subsection{Protocol and Registration}

The present systematic review was performed following the PRISMA (Preferred Reporting Items for Systematic Review and Meta-Analyses) statement [11].

\subsection{Eligibility Criteria}

All ex vivo studies performing a fracture strength test on premolars, extracted for orthodontic and periodontal reasons were included in the present protocol. Inclusion criteria were defined with the $\mathrm{PICO}(\mathrm{S})$ method:

- Population: intact premolars or with $0 / 1 / 2$ walls lost (i.e., intact premolars, or premolars without the involvement of any of the 4 walls, or premolars with either the mesial or distal wall lost, or premolars with both the mesial and distal walls lost);

- Intervention: fracture strength test;

- Comparison: no comparison group was defined;

- Outcome: fracture strength, measured in Newton;

- Studies: all ex vivo studies.

\section{Exclusion Criteria}

All studies where an indirect restoration, fiber post or endocrown were performed, were excluded from the current protocol.

\subsection{Information Sources}

The search strategy included the screening of electronic databases and the relevant journals. Other sources encompassed citations from relevant articles. The screening and inclusion stages were reported following the PRISMA flow diagram (Figure 1).

\subsubsection{Electronic Search}

The electronic databases screened were MEDLINE (through Pubmed) and Google Scholar; a search for grey literature was also carried out (OpenGrey). A combination of $\mathrm{MeSH}$ terms and free text words was used to define the full electronic strategy. Only studies published in English or Italian were included; no restrictions as to publication date were applied.

The full electronic search strategy is reported for MEDLINE (through PubMed):

Fracture Strength Test AND (endodontics OR endodontically treated teeth).

The search strategy was then adapted for the other databases.

\subsubsection{Hand Search}

Relevant journals (Journal of Endodontics, International Journal of Endodontics, Journal of Prosthetic Dentistry) were screened by two independent reviewers (C.M., C.G.), assessing all issues from January 1985 until June 2021. Other sources encompass narrative reviews and references from relevant articles. 

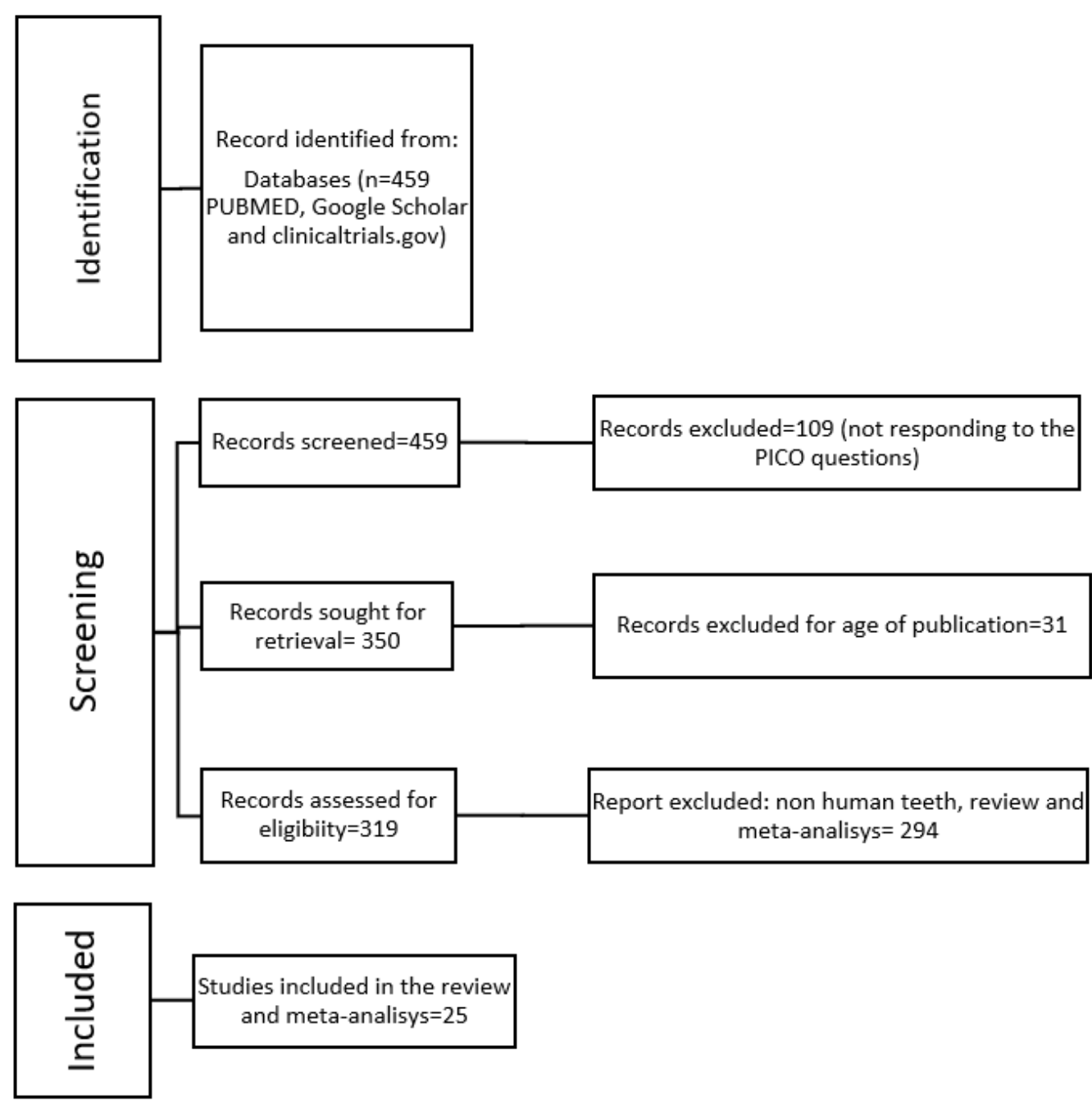

Figure 1. PRISMA flow diagram summarizing all inclusion criteria.

\subsection{Study Selection}

Titles and abstracts were independently screened for relevance by two calibrated reviewers (un-weighted Cohen's $k$ score of 0.90) (C.M., C.G.). Subsequently, the preselected articles were screened for full-text analysis by both reviewers according to the eligibility criteria. Any disagreement at any stage (title/abstract or full text) was resolved through discussion with a third author (S.G.) in order to reach consensus.

\subsection{Data Collection Process}

Data collection was performed through an extraction sheet by two independent reviewers (C.M., C.G.) during full-text analysis. Characteristics of the included studies encompassed: fracture strength test of intact upper premolars or with, 0,1 and 2 walls lost.

\subsection{Data Items}

The primary outcome of the protocol was defined as the maximum fracture strength value expressed in Newton $\left(\mathrm{kg} \times \mathrm{m} / \mathrm{s}^{2}\right)$. The methodological variables such as Periodontal Ligament (PDL) simulation, inclination of the load, tip position and diameter, thermocycling were registered and used to perform subgroup analysis and meta-regression.

\subsection{Summary Measures}

In the present systematic review, fracture strength values were considered as the main outcome and a precomputed effect size with $95 \%$ Confidence Interval was calculated. Whenever it was not available, fracture strength was calculated through raw data analysis. 


\subsection{Synthesis of Results and Additional Analyses}

Statistical analysis was carried out through an ad hoc statistical software (STATA BE, version 17, StataCorp LP, College Station, TX, USA).

Cochran's $Q$ statistic and the $I^{2}$ index were used in order to estimate heterogeneity across studies. Between-study variance was estimated with the $\mathrm{T}^{2}$ parameter. Meta-analysis of the included studies was conducted through an inverse variance analysis using the Der Simonian and Laird random effects model. The analysis was performed using the pre-computed effect size pooled for each study. Subgroup analysis was performed (for each group: intact premolars, 0, 1, 2 walls lost) about the following variables:

Periodontal ligament simulation;

Load inclination;

Tip position;

Thermocycling;

Meta-regression of the covariate Tip diameter was also performed. The obtained results were graphically showed by forest plot. Moreover, publication bias was assessed through the Egger's test. Values of $p<0.05$ were considered statistically significant.

\section{Results}

\subsection{Study Selection}

Initial electronic search retrieved a total of 459 articles in MEDLINE. Manual search in relevant journals led to no additional records. 31 were excluded because for age of publication. After the exclusion of 294 records at the eligibility level, 134 were assessed for full-text eligibility. Finally, 25 studies were included in both the qualitative and quantitative (meta-analysis) synthesis of data, from which 17 subgroups were extrapolated for Intact premolar, 17, 6, 45 respectively for 0, 1, 2 walls lost. Inter-examiner agreement for articles inclusion resulted in a Cohen's $k$-score of 0.90 . The study selection process is depicted in Figure 1. Characteristics of the included studies are described in Table 1.

\subsection{Descriptive Analysis}

Intact premolars

Out of 17 subgroups, the load inclination applied was $90^{\circ}$ for nine $[10,12-19]$ and $30^{\circ} / 45^{\circ}$ for eight [19-24]. PDL simulation was performed in five subgroups $[10,12,15,22,25]$ while thermocycling was applied in five $[10,12,15,23,26]$. Tip diameter was respectively lower than $2 \mathrm{~mm}$ and between 2 and $3 \mathrm{~mm}$ in one group, between 3 and $5 \mathrm{~mm}$ in four groups, $6 \mathrm{~mm}$ in seven groups and $8 \mathrm{~mm}$ in two groups.

Premolar with 0 wall lost

Out of 17 subgroups, the load inclination applied was $90^{\circ}$ for two [27] and $45^{\circ}$ for six $[17,19,28]$. Thermocycling simulation was performed in two subgroups $[17,29]$ while no PDL simulation was applied. Tip diameter was respectively $3 \mathrm{~mm}$ in three groups and 6 in seven.

Premolar with 1 wall lost

Out of 6 subgroups, the load inclination applied was $90^{\circ}$ for four $[14,28,30]$ and $45^{\circ}$ for two [14]. Thermocycling was performed in one subgroup [14] while no PDL simulation was applied. Tip diameter used was between 2 and $3 \mathrm{~mm}$ in one group while in the remaining was not specified.

Premolar with 2 walls lost

Out of 45 subgroups, the load inclination applied was $90^{\circ}$ for twenty-four [10,12,22,30-34] and $30^{\circ} / 45^{\circ}$ for twenty-one $[10,13,15,19,23,28,35,36]$. PDL simulation was performed in twelve subgroups $[10,15,22,30,31]$ while thermocycling was applied in six $[10,30,31]$. Tip diameter was respectively $3 \mathrm{~mm}$ in three groups and 6 in seven. Tip diameter was respectively lower than $2 \mathrm{~mm}$ in nine and between 2 and $3 \mathrm{~mm}$ in one group: between 3 and $5 \mathrm{~mm}$ in four groups, $6 \mathrm{~mm}$ in thirteen groups and $8 \mathrm{~mm}$ in seven. In remaining groups, the tip diameter was not specified. 


\subsection{Meta-Analysis}

Intact premolars

Thirteen groups were included for meta-analysis with very high heterogeneity value $\left(I^{2}=99.90 \%\right)$ (Figures 2-5) while publication bias was not present $(p>0.05)$ (Supplementary Materials, Figure S1). Subgroup analysis showed that none of the variables analyzed, influences the fracture strength value in intact premolars $(p>0.05)$ (Table 2). Meta-regression of the tip diameter did not influence the fracture strength of the intact premolar.

Table 1. characteristics of the included studies.

\begin{tabular}{|c|c|c|c|c|c|c|c|}
\hline Authors & Years & Teeth & $\mathbf{N}$ & PDL & Thermocycling & Load Inclination & Tip Application \\
\hline Gokturk & 2018 & Upper & 55 & + & + & $90^{\circ}$ & Buccal/Lingual cusp \\
\hline $\mathrm{Oz}$ & 2019 & Upper & 80 & + & + & $90^{\circ}$ & Occlusal surface \\
\hline Eapen & 2017 & Upper & 60 & - & - & $90^{\circ}$ & $\begin{array}{l}\text { Occlusal inclines of the Buccal and } \\
\text { Lingual cusps }\end{array}$ \\
\hline Harsha & 2017 & Upper 1 st & 40 & - & + & $30^{\circ}$ & On the Center of the Buccal cusp \\
\hline Desai & 2011 & Upper1 st & 30 & - & + & $90^{\circ}$ & Center occlusal surface \\
\hline Kemaloglu & 2015 & Lower & 48 & + & - & $90^{\circ}$ & B and L cusps simultaneously \\
\hline Zogheib & 2018 & Upper & 60 & + & - & $90^{\circ}$ & Central fossa \\
\hline Karzoun & 2015 & Upper & 60 & + & - & $90^{\circ}$ & / \\
\hline Taha & 2014 & Upper & 48 & - & - & $45^{\circ}$ & / \\
\hline Hshad & 2018 & Lower & 48 & - & - & $90^{\circ}$ & Interdental surface of the buccal cusp \\
\hline Angol & 2013 & Upper & 10 & - & - & $90^{\circ}$ & $\begin{array}{c}\text { Simultaneous contact B and P cuspal } \\
\text { inclines }\end{array}$ \\
\hline Taha & 2011 & Upper & 80 & - & - & $45^{\circ}$ & Palatal incline of Buccal cusp \\
\hline Taha & 2015 & Upper & 77 & - & - & $45^{\circ}$ & Palatal incline of Buccal cusp \\
\hline Mashyakhy & 2020 & / & 52 & + & + & $90^{\circ}$ & Center occlusal surface \\
\hline Spicciarelli & 2020 & $\begin{array}{l}\text { Upper 1st } \\
\text { (1 root) }\end{array}$ & 165 & - & - & $90^{\circ}$ & $\begin{array}{l}2 \mathrm{~mm} \text { from apex of Palatal cusp in the } \\
\text { direction of Central fossa }\end{array}$ \\
\hline Monga & 2009 & Upper & 80 & - & - & $90^{\circ}$ & $\begin{array}{l}\text { Occlusal inclines of the buccal and } \\
\text { lingual cusps }\end{array}$ \\
\hline Soares & 2008 & / & 50 & + & - & $45^{\circ}$ & Buccal and lingual cusps \\
\hline Sengun & 2008 & Lower & 80 & + & - & $45^{\circ}$ & Central fossa with lingual orientation \\
\hline Soares & 2008 & $\begin{array}{l}\text { Upper } \\
\text { (1 root) }\end{array}$ & 50 & + & - & $90^{\circ}$ & Center occlusal surface \\
\hline Shahrbaf & 2007 & Upper & 60 & - & + & $45^{\circ}$ & Palatal cusp \\
\hline Coelho & 2005 & Upper & 90 & - & - & $90^{\circ}$ & $\begin{array}{l}\text { Buccal and Lingual inclined cuspal } \\
\text { planes, not restoration }\end{array}$ \\
\hline Mondelli & 2007 & Upper 1st & 40 & - & - & $90^{\circ}$ & Contacted both cusps simultaneously \\
\hline Skupien & 2016 & $\begin{array}{l}\text { Upper } \\
\text { (1 root) }\end{array}$ & 30 & - & + & $45^{\circ}$ & Torward buccal cusp \\
\hline Plotino & 2017 & Upper 1st & 20 & - & - & $30^{\circ}$ & Central fossa \\
\hline Gurel & 2016 & $\begin{array}{l}\text { Upper } \\
\text { (1 root) }\end{array}$ & 80 & - & - & $30^{\circ}$ & Central fissure of the occlusal surface \\
\hline
\end{tabular}

Premolar with 0 wall lost

A meta-analysis was performed with 10 groups. The Heterogeneity was very high $\left(I^{2}=97.73 \%\right)$ (Figure 6), and the publication bias was present $(p=0.00)$ (Supplementary Materials, Figure S2). PDL simulation significantly influences the fracture strength test $(p=0.00)$, as well as the $90^{\circ}$ tip inclination when compared with $30 / 45^{\circ}(p=0.00)$ (Table 3). Tip position and thermocycling does not affect the fracture strength test of premolars with 0 wall lost $(p>0.05)$. Meta-regression of tip diameter does not seem to affect the test $(p>0.05)$. 


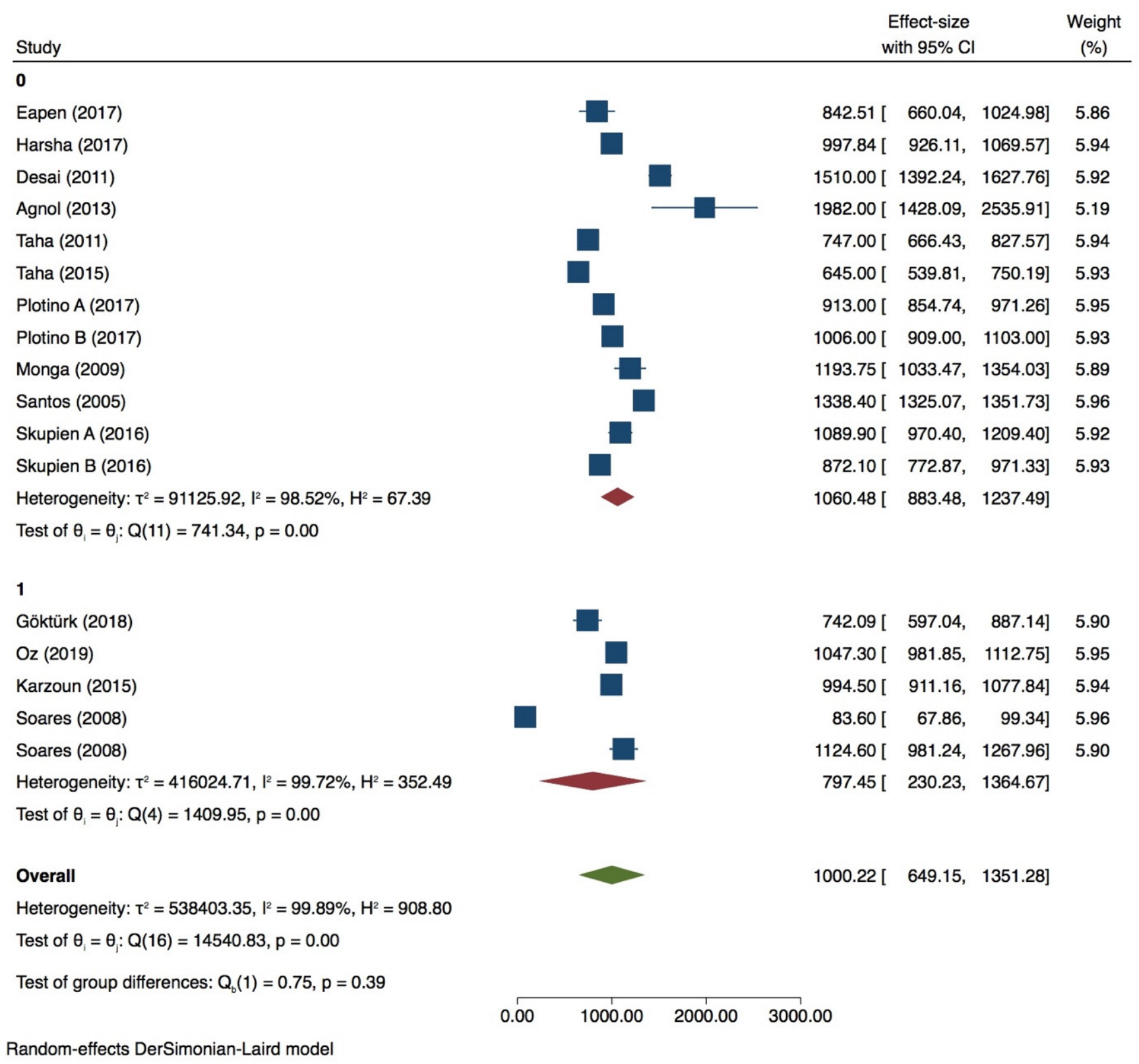

Figure 2. Forest plots for intact premolars of PDL simulation.

Premolar with 1 wall lost

6 groups were included in the meta-analysis. Despite a high heterogeneity $\left(I^{2}=97.73 \%\right)$ (Figure 4$)$, publication bias was not present $(p>0.05)$ as shown also by the funnel plot (Supplementary Materials, Figure S3). Tip position and thermocycling significantly influence the test on premolar with 1 wall lost $(p=0.00)$ (Figure 7$)$, while inclination did not $(p>0.05)$ (Table 4). 


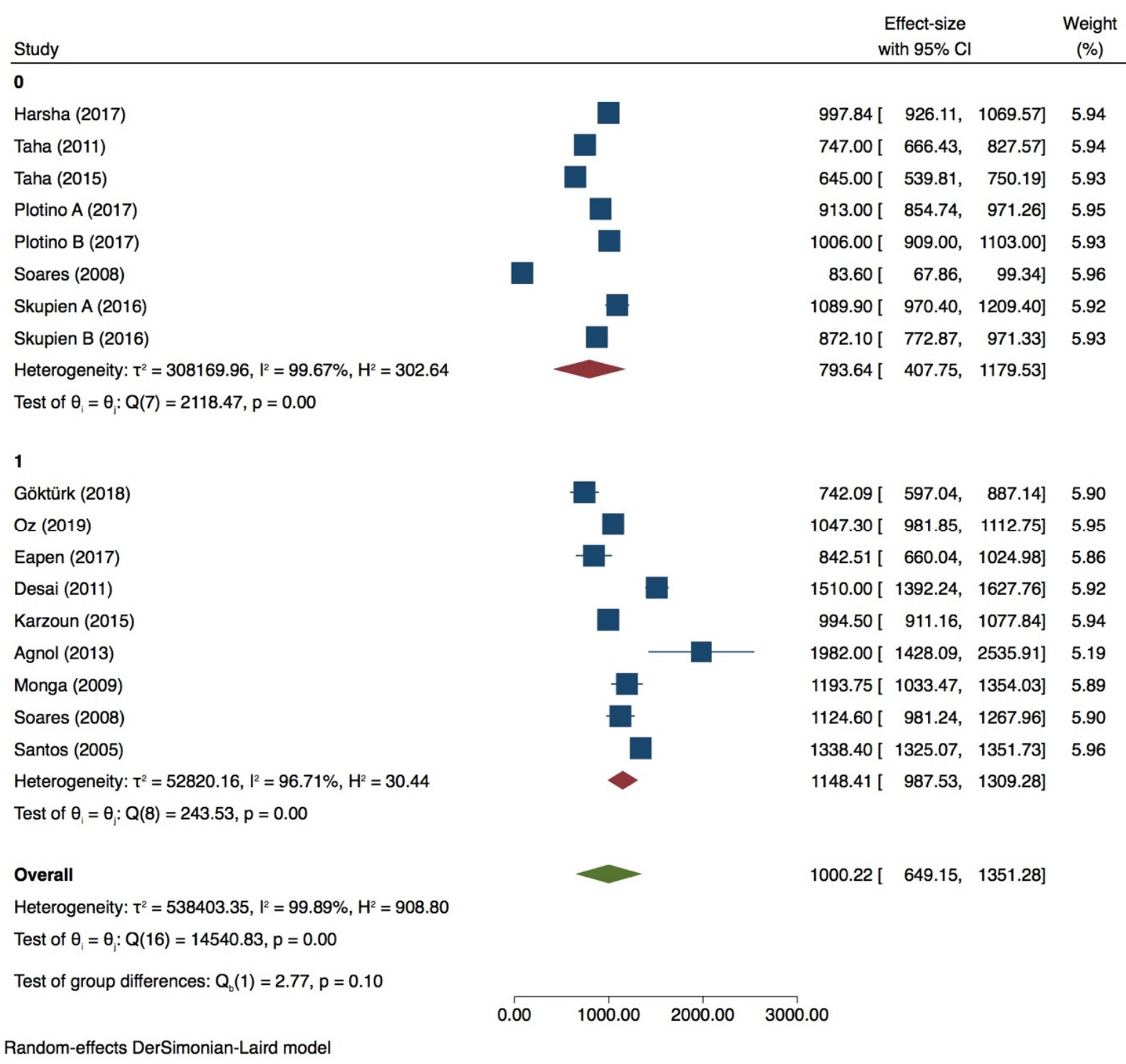

Figure 3. Forest plot for intact premolars in load inclination subgroup.

Premolar with 2 walls lost

A meta-analysis conducted with 45 groups showed a very high heterogeneity $\left(I^{2}=99.91 \%\right)$ (Figure 8), and the Egger test indicated the presence of publication bias $(p<0.05)$ (Supplementary Materials, Figure S4). PDL simulation showed no influence on the fracture strength test $(p>0.05) .90^{\circ}$ tip inclination significantly affected the test compared to $30 / 45^{\circ}$ $(p=0.05)$ (Figure 9$)$. Neither the tip position nor the diameter seemed to influence the results of the in vitro test $(p>0.05)$ (Table 5). 


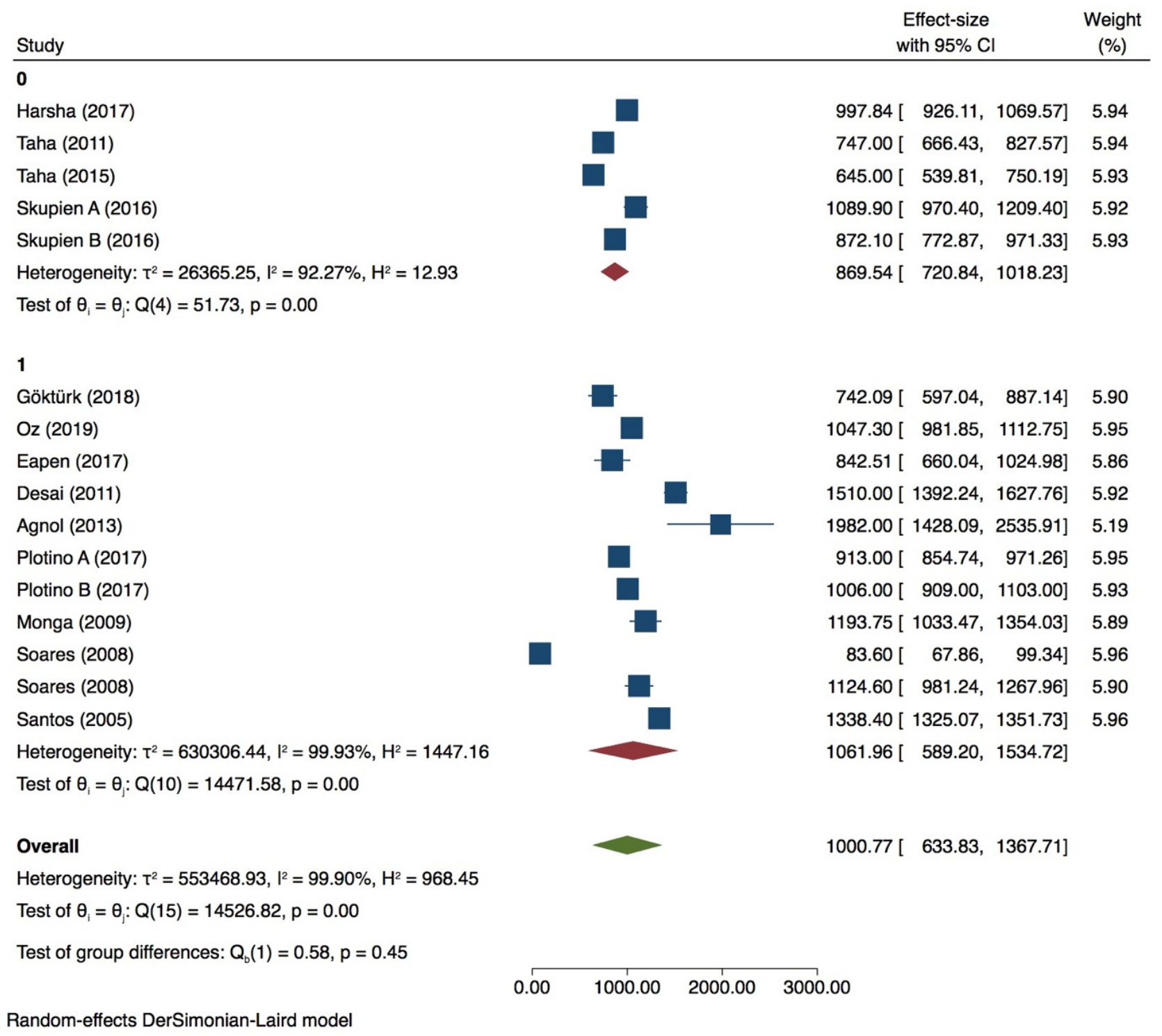

Figure 4. Forest plot for intact premolars in tip position subgroup.

Table 2. Heterogeneity summary, PDL Simulation, Load Inclination, Tip Position, Thermocycling in intact premolar subgroup.

Heterogeneity summary: PDL simulation (Binary; $0=-\mathrm{PDL} ;+\mathrm{PDL}$ )

Number of studies: 17

\begin{tabular}{|c|c|c|c|c|c|c|}
\hline Group & $\mathrm{df}$ & Q & $P>Q$ & Tau $^{2}$ & $\% \mathrm{I}^{2}$ & $\mathrm{H}^{2}$ \\
\hline 0 & 11 & 741.34 & 0.000 & $91,125.915$ & 98.52 & 67.39 \\
\hline 1 & 4 & 1409.95 & 0.000 & $4.16 \mathrm{e}+05$ & 99.72 & 352.49 \\
\hline Overall & 16 & 396.53 & 0.000 & $5.38 \mathrm{e}+05$ & 99.98 & 908.80 \\
\hline \multicolumn{5}{|c|}{$\begin{array}{l}\text { Test of group differences: } Q \_b=\operatorname{chi}^{2}(1)=0.75 \\
\text { Heterogeneity summary: Load inclination }\left(\text { Binary; } 0=30 / 45^{\circ} ; 1=90^{\circ}\right) \\
\text { Number of studies: } 17\end{array}$} & & $b=0.386$ \\
\hline Group & $\mathrm{df}$ & $Q$ & $P>Q$ & $\mathrm{Tau}^{2}$ & $\% \mathrm{I}^{2}$ & $\mathrm{H}^{2}$ \\
\hline 0 & 7 & 2118.47 & 0.000 & $3.08 \mathrm{e}+05$ & 99.67 & 302.64 \\
\hline 1 & 8 & 243.53 & 0.000 & $52,820.161$ & 96.71 & 30.44 \\
\hline Overall & 16 & $14,540.83$ & 0.000 & $5.38 \mathrm{e}+05$ & 97.73 & 908.80 \\
\hline
\end{tabular}


Table 2. Cont.

Test of group differences: $Q \_b=\operatorname{chi}^{2}(1)=2.77$

Prob > Q_b $=0.096$

Heterogeneity summary: Tip Position (Binary; $0=$ either buccal or lingual; $1=$ central fossa or both cusps)

Number of studies: 17

\begin{tabular}{ccccccc}
\hline Group & $\mathrm{df}$ & $\mathrm{Q}$ & $\mathrm{P}>\mathrm{Q}$ & $\mathrm{Tau}^{2}$ & $\% \mathrm{I}^{2}$ & $\mathrm{H}^{2}$ \\
\hline 0 & 4 & 51.73 & 0.000 & $26,365.250$ & 92.27 & 12.93 \\
1 & 10 & $14,471.58$ & 0.000 & $6.30 \mathrm{e}+05$ & 99.93 & 1447.16 \\
\hline Overall & 9 & $14,526.82$ & 0.000 & $5.53+05$ & 99.90 & 968.45
\end{tabular}

Test of group differences: $\mathrm{Q} \_\mathrm{b}=\mathrm{chi}^{2}(1)=0.58 \quad$ Prob $>\mathrm{Q} \_\mathrm{b}=0.447$

Heterogeneity summary: Thermocycling (Binary; $0=-$ Therm; +Therm)

Number of studies: 17

\begin{tabular}{ccccccc}
\hline Group & $\mathrm{df}$ & $\mathrm{Q}$ & $\mathrm{P}>\mathrm{Q}$ & $\mathrm{Tau}^{2}$ & $\% \mathrm{I}^{2}$ & $\mathrm{H}^{2}$ \\
\hline 0 & 11 & $14,351.13$ & 0.000 & $5.93 \mathrm{e}+05$ & 73.46 & 3.77 \\
1 & 4 & 88.66 & 0.000 & $58,364.924$ & 98.98 & 97.81 \\
\hline Overall & 16 & $14,540.83$ & 0.000 & $5.38 \mathrm{e}+05$ & 97.73 & 44.06
\end{tabular}

$\begin{array}{ll}\text { Test of group differences: } Q \_b=\operatorname{chi}^{2}(1)=0.09 & \text { Prob }>\text { Q_b }=0.766\end{array}$

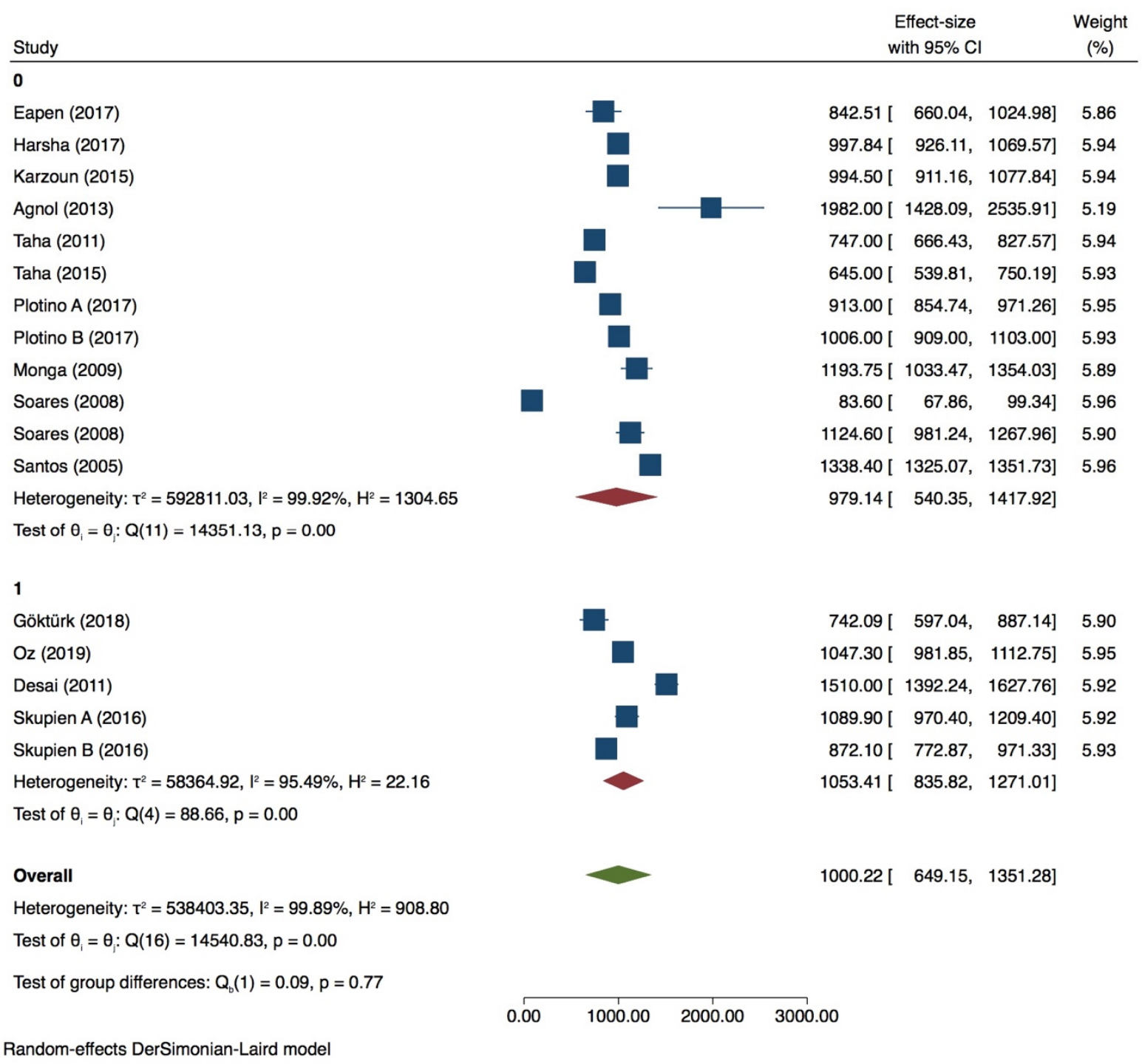

Figure 5. Forest plot of intact premolars in thermocycling subgroup. 


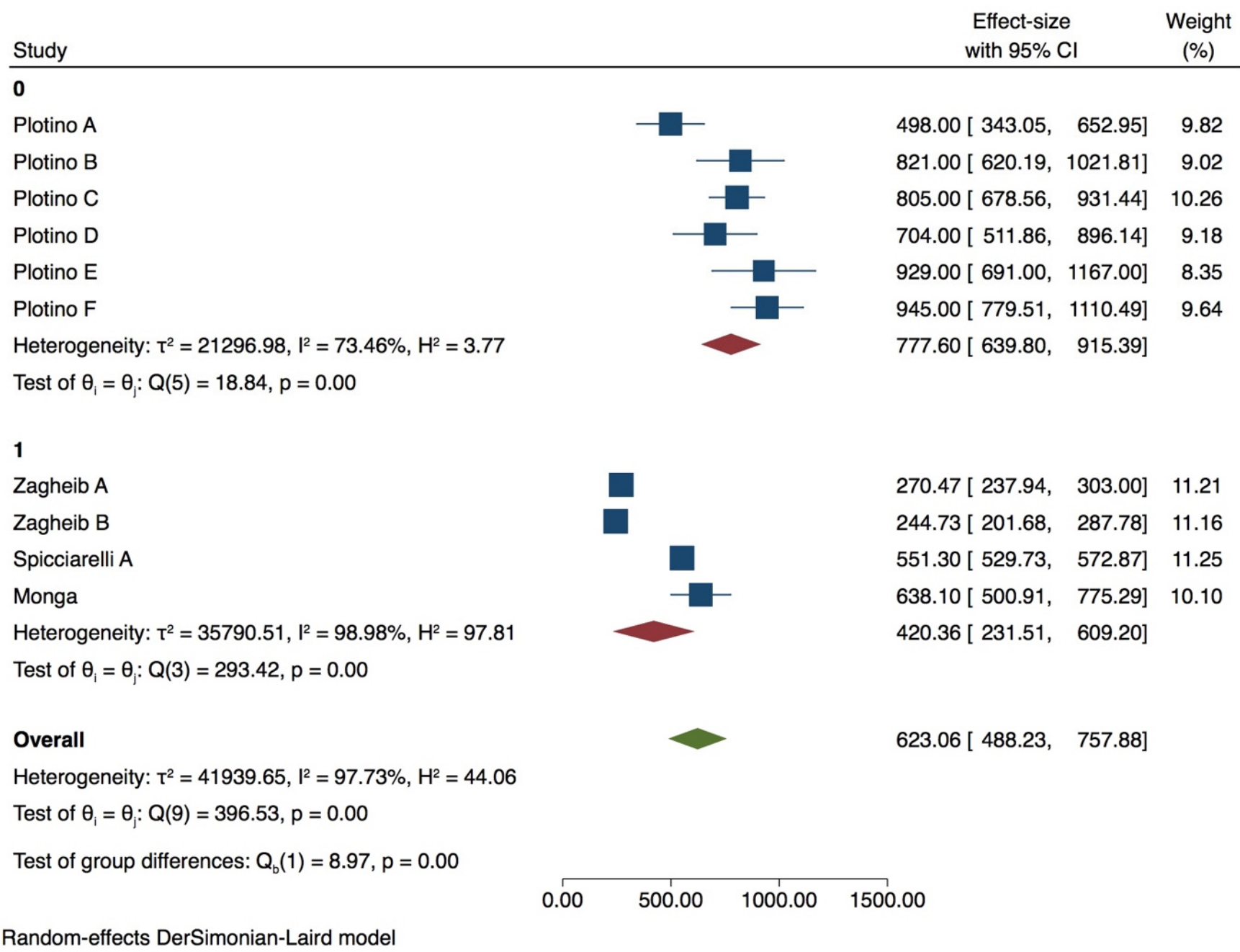

Figure 6. Forest plot of premolar with 0 wall loss of tip inclination variable.

Table 3. Summarizing of results in subgroups with 0 walls lost.

\begin{tabular}{|c|c|c|c|c|c|c|}
\hline \multicolumn{7}{|c|}{$\begin{array}{l}\text { Heterogeneity summary: Load inclination (Binary; } 0=30 / 45^{\circ} ; 1=90^{\circ} \text { ) } \\
\text { Number of studies: } 10\end{array}$} \\
\hline Group & $\mathrm{df}$ & $Q$ & $P>Q$ & $\mathrm{Tau}^{2}$ & $\% \mathrm{I}^{2}$ & $\mathrm{H}^{2}$ \\
\hline 0 & 5 & 18.84 & 0.002 & $21,296.981$ & 73.46 & 3.77 \\
\hline 1 & 3 & 293.42 & 0.000 & $35,790.506$ & 98.98 & 97.81 \\
\hline Overall & 9 & 396.53 & 0.000 & $41,939.649$ & 97.73 & 44.06 \\
\hline \multicolumn{5}{|c|}{ Test of group differences: Q_b $=\mathrm{chi}^{2}(1)=8.97$} & \multicolumn{2}{|c|}{ Prob $>$ Q_b $=0.00$} \\
\hline
\end{tabular}




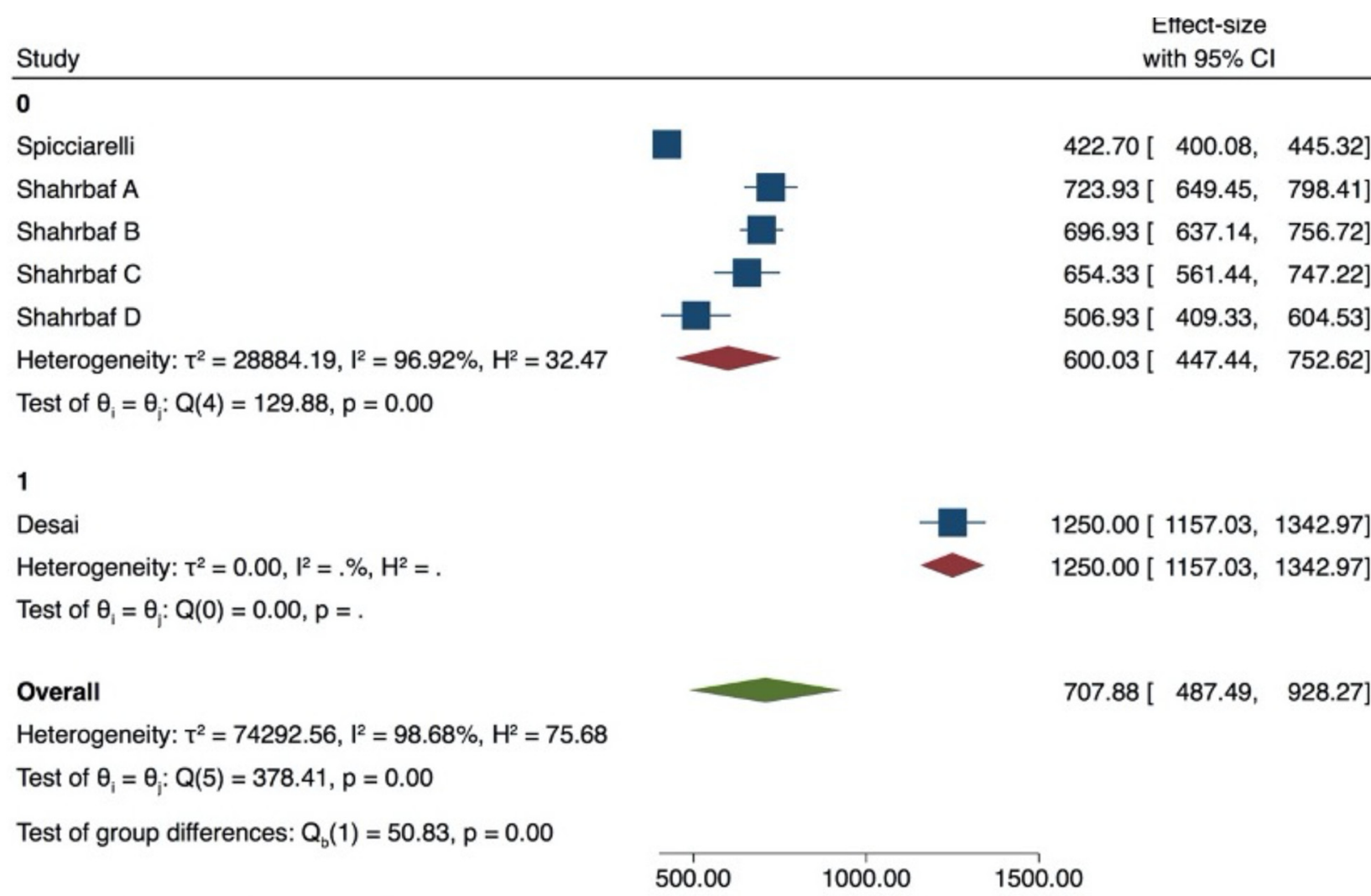

(0)

Spicciarelli

Shahrbaf A

Shahrbaf $C$

Shahrbaf D

Heterogeneity: $\mathrm{T}^{2}=28884.19, \mathrm{I}^{2}=96.92 \%, \mathrm{H}^{2}=32.47$

$\begin{array}{lll}500.00 & 1000.00 & 1500.00\end{array}$

Random-effects DerSimonian-Laird model

Effect-size with $95 \% \mathrm{Cl}$

422.70 [ 400.08, 445.32] 16.99

Spicciarelli

Shahrbaf A

Shahrbaf B

Shahrbaf C

Shahrbaf D

Heterogeneity: $\mathrm{T}^{2}=28884.19, \mathrm{I}^{2}=96.92 \%, \mathrm{H}^{2}=32.47$

Test of $\theta_{i}=\theta_{i}: Q(4)=129.88, p=0.00$

1

Desai

Heterogeneity: $\mathrm{t}^{2}=0.00, \mathrm{l}^{2}=. \%, \mathrm{H}^{2}=$.

Test of $\theta_{i}=\theta_{i}: Q(0)=0.00, p=$.

\section{Overall}

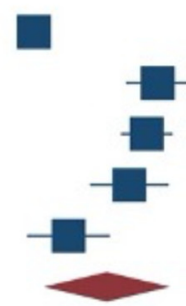

723.93 [ $649.45,798.41] 16.69$

696.93 [ $637.14,756.72] 16.81$

654.33 [ $561.44,747.22] 16.52$

506.93 [ 409.33, 604.53] 16.47

$600.03[447.44,752.62]$

1250.00 [ 1157.03, 1342.97] 16.52

1250.00 [ 1157.03, 1342.97]

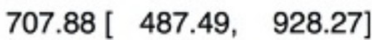

Heterogeneity: $\mathrm{T}^{2}=74292.56, \mathrm{I}^{2}=98.68 \%, \mathrm{H}^{2}=75.68$

Test of $\theta_{i}=\theta_{i}: Q(5)=378.41, p=0.00$

Test of group differences: $Q_{b}(1)=50.83, p=0.00$

\begin{tabular}{lll}
\hline 500.00 & $1000.00 \quad 1500.00$
\end{tabular}

Random-effects DerSimonian-Laird model

Figure 7. Forest plots of thermocycling and tip position in premolar with 1 wall lost. 


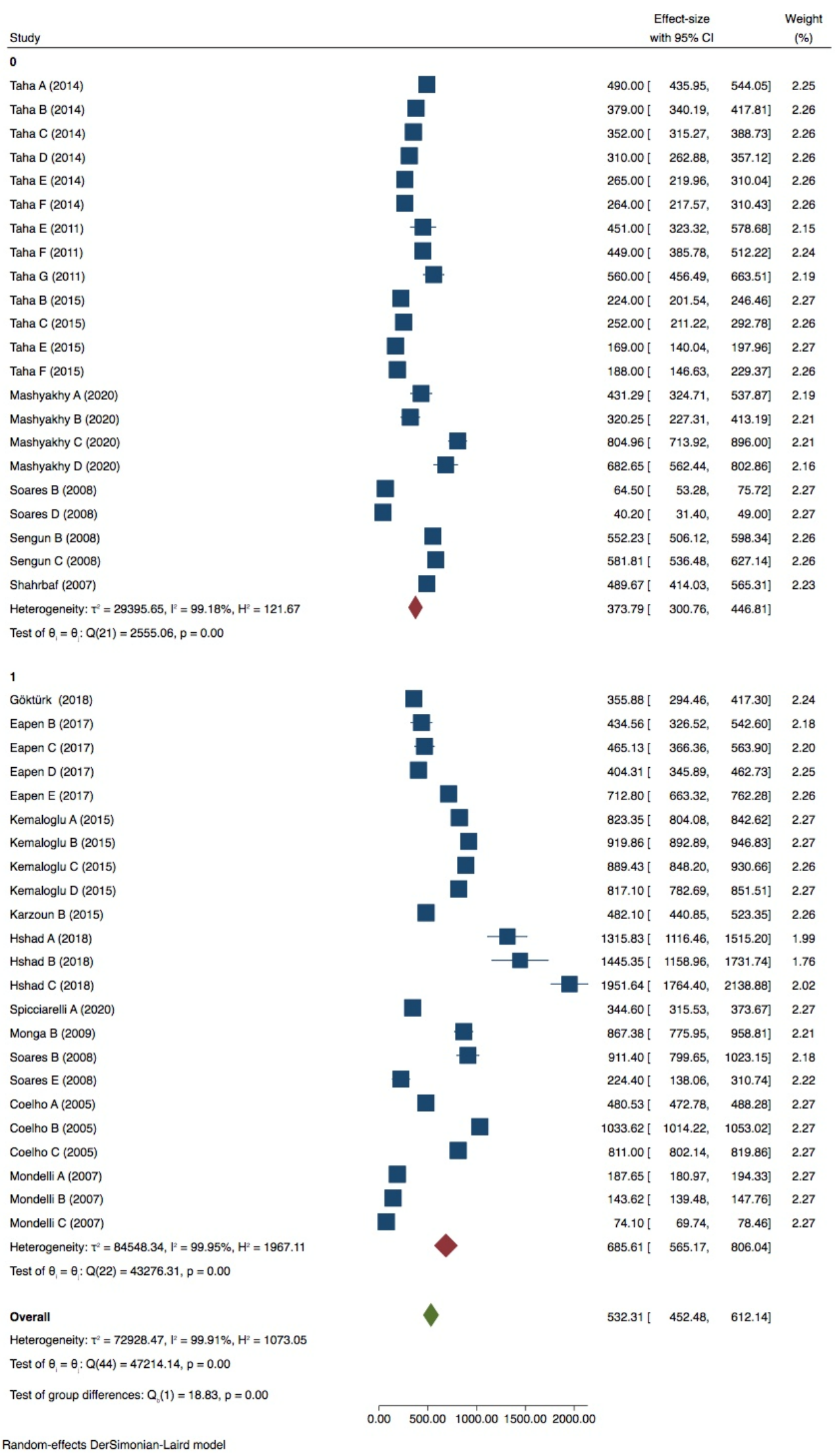

Figure 8. Forest plot of in premolar with 2 walls lost group. 


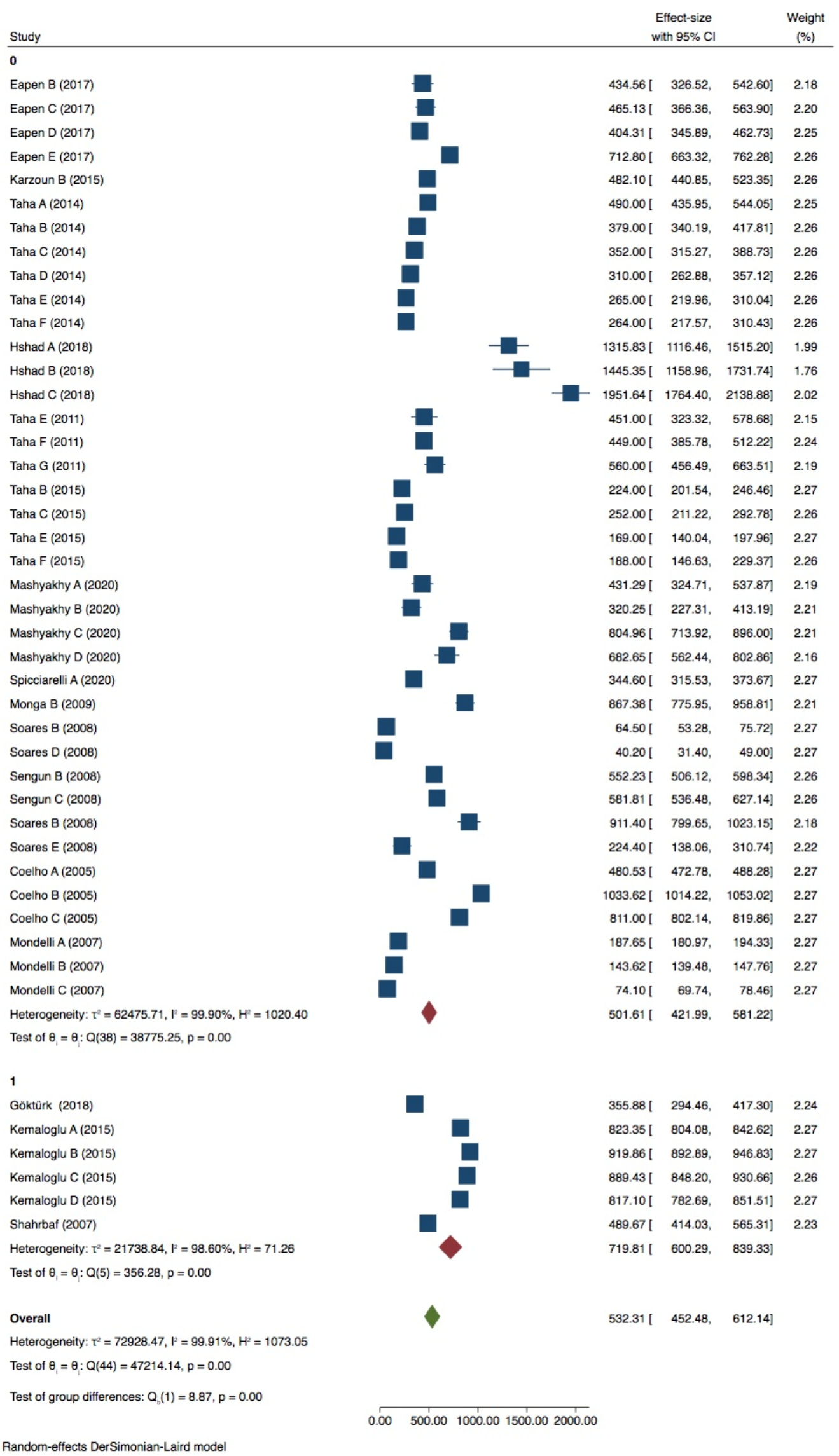

Figure 9. Forest plot of tip inclination in premolar with 2 walls lost. 
Table 4. Summarizing of load inclination and thermocycling subgroup results with 1 wall lost.

\begin{tabular}{|c|c|c|c|c|c|c|}
\hline \multicolumn{7}{|c|}{$\begin{array}{l}\text { Heterogeneity summary: Load inclination (Binary; } 0=30 / 45^{\circ} ; 1=90^{\circ} \text { ) } \\
\text { Number of studies: } 6\end{array}$} \\
\hline Group & $\mathrm{df}$ & $\mathrm{Q}$ & $P>Q$ & $\mathrm{Tau}^{2}$ & $\% \mathrm{I}^{2}$ & $\mathrm{H}^{2}$ \\
\hline 0 & 0 & 0.00 & - & 0.000 & - & - \\
\hline 1 & 4 & 378.35 & 0.000 & $84,712.462$ & 98.94 & 94.59 \\
\hline Overall & 5 & 378.41 & 0.000 & $74,292.555$ & 98.68 & 75.68 \\
\hline \multicolumn{7}{|c|}{$\begin{array}{l}\text { Test of group differences: } Q \mathrm{Q} b=\mathrm{chi}^{2}(1)=2.94 \\
\text { Heterogeneity summary: Thermocycling (Binary; } 0=- \text { Therm; +Therm) } \\
\text { Number of studies: } 6\end{array}$} \\
\hline Group & Df & Q & $P>Q$ & $\mathrm{Tau}^{2}$ & $\% \mathrm{I}^{2}$ & $\mathrm{H}^{2}$ \\
\hline 0 & 4 & 129.88 & 0.000 & $28,884.187$ & 73.46 & 3.77 \\
\hline 1 & 0 & 0.00 & - & 0.000 & 98.98 & 97.81 \\
\hline Overall & 5 & $14,540.83$ & 0.000 & $74,292.555$ & 97.73 & 44.06 \\
\hline
\end{tabular}

Table 5. Meta-regression of tip diameter in subgroup with 0 and 2 walls lost.

\begin{tabular}{|c|c|c|c|c|c|}
\hline Meta es & Coef. & Std. Err. & $\mathbf{z}$ & $\mathbf{P}>\mathbf{z}$ & [95\% Conf.Interval] \\
\hline Tip diameter & 108.9722 & 109.2411 & 2.24 & 0.025 & $\begin{array}{l}13.43596 \\
204.5084\end{array}$ \\
\hline cons & 92.22167 & 251.3299 & 0.37 & 0.714 & $\begin{array}{c}-400.3759 \\
584.8193\end{array}$ \\
\hline \multicolumn{5}{|c|}{ Test of group differences: Q_res $=\mathrm{chi}^{2}(13)=396.23$} & Prob $>$ Q_res $=0.0000$ \\
\hline Tip diameter & 54.2533 & 21.42337 & 2.53 & 0.011 & $\begin{array}{l}12.26426 \\
96.24234\end{array}$ \\
\hline cons & 272.2454 & 114.956 & 2.37 & 0.018 & $\begin{array}{c}46.93586 \\
497.555\end{array}$ \\
\hline \multicolumn{5}{|c|}{ Test of group differences: Q_res $=$ chi2 $(13)=9033.13$} & Prob $>$ Q_res $=0.0000$ \\
\hline
\end{tabular}

\section{Discussion}

\subsection{Summary of Findings}

In the present meta-analysis, we evaluated the impact of methodological variables such as periodontal ligament simulation, tip diameter, position and inclination, thermo cycling in the fracture strength test on the upper premolar with different residual walls. Studies regarding premolars were chosen because of their natural tendency to be more prone to fracture compared to other teeth, although anatomical variables such as crown volume and inclination of the cusp could affect the strength of the tooth. According to the results of the present study, all methodological variables, including periodontal ligament simulation, thermocycling, tip position and diameter, load inclination, do not seem to affect fracture strength test in the intact premolar, whereas a very significant publication bias and high heterogeneity were present in this subgroup. In this group the fracture strength does not seem to be affected by the variables analyzed, showing, as expected, the higher value of fracture strength compared to other groups as confirmed previously by da Angol et al. [20] and Jantarat et al. [37]. This could be explained by the homogeneous distribution of load force transferred from the rigid intact enamel to the underlying dentin as demonstrated by Ausiello [38]. Periodontal ligament simulation influences the fracture strength test only in the premolar with 0 wall lost in respect to the other three groups examined in this review. Periodontal ligament represents an important anatomical structure able to absorb the occlusal forces during chewing function and should be reproduced in the "in vitro test" in order to simulate the clinical reality. Rees [8] underlined the importance of simulating 
the periodontal ligament in the fracture strength test by a finite element analysis. In any case, many materials were utilized to perform these procedures and a lack of uniformity between studies was observed in the review analysis.

Metaregression regarding the variable tip diameter seemed to not influence the test in any case. In addition, in this case, new studies are needed to understand if the diameter of the tip could influence the fracture strength test. The load inclination seemed to influence the fracture strength test when the force was applied at $30 / 45^{\circ}$ instead of perpendicular, except for premolars with 0 wall lost. Yang [39] showed that the direction of the force decreases the fracture strength as the walls lost increase. The same results were obtained by Reeh [8] in case of endodontically treated teeth, demonstrating a higher resistance to fracture when conservative cavity access was applied. According to our data, thermocycling seems to influence with statistical significance the data of the fracture strength test mostly in the case of premolars with 1 and 2 walls lost, showing higher resistance to fracture when the procedure was applied. Our results are in agreement with Sabery [40] regarding intact premolars, whereas his showed that thermocycling influenced the fracture strength values in the case of different cavity preparation. These data could be explained by the fact that thermocycling is applied to put in evidence teeth with crack or fracture already present which could influence the results of the test.

\subsection{Strengths and Limitations}

The current review represents the first meta-analytical analysis of the methodological variables present in the fracture strength and their influence on the test results. The strict methodology used according with new PRISMA guidelines, the high number of the included study as well as the high number of the methodological variables analyzed represent the strength of the present study. Despite the lack of publication bias, outcome reporting bias could be present, affecting the heterogeneity of the selected studies. In fact, despite additional analysis, it was impossible to reduce the heterogeneity, thus suggesting that other methodological variables, as well as ignoring non-significant outcomes, which could not be considered, may have influenced the results. The present meta-analysis showed high heterogeneity values in all groups analyzed and this represents the main limitation of the present study in which the results should be considered with caution.

Data were scarce about periodontal ligament simulation, tip position and diameter and in any case, our meta-analysis fails to detect a statistical significance in the fracture strength test, despite it having been observed that a decrease of the tip diameter matches a lower resistance to fracture [37]. Another limitation of this systematic review is represented by the lack of information regarding the choice of what upper premolar has been used. Taha et al. [5] reported the influence of shape difference of cervical area between first and second premolar in the fracture susceptibility.

\section{Conclusions}

Fracture strength test is the main in vitro study able to better understand the capacity of dental materials to resist under stress conditions and in various clinical situations. Despite the numerous studies already published in the literature, there is an evident lack of uniformity. The present meta-analysis highlights the necessity to standardize the procedure in order to reduce the variability of fracture strength test results.

Supplementary Materials: The following are available online at https:/ / www.mdpi.com/article/10 .3390/dj9120146/s1, Figure S1: funnel plot for intact premolar group, Figure S2: funnel plot for 0 wall lost group; Figure S3: funnel plot for 1 wall lost group; Figure S4: funnel plot for 2 walls lost group.

Author Contributions: Conceptualization, C.G. and C.M.; methodology, C.G.; formal analysis, G.F. and C.M.; investigation, C.G. and C.M.; writing-original draft preparation, C.G. and C.M.; writingreview and editing, E.F., E.M. and S.G.; funding acquisition, S.G. All authors were involved in the experimental ideas and critically revised the manuscript. All authors have read and agreed to the published version of the manuscript. 
Funding: This research received no external funding.

Conflicts of Interest: The authors declare no conflict of interest.

\section{References}

1. Eakle, W. Fracture Resistance of Teeth Restored with Class II Bonded Composite Resin. J. Dent. Res. 1986, 65, 149-153. [CrossRef]

2. Krejci, I.; Dietschi, D. Marginal adaptation, retention and fracture resistance of adhesive composite restorations on devital teeth with and without posts. Oper Dent. 2003, 28, 127-135. [PubMed]

3. Tang, W.; Wu, Y.; Smales, R. Identifyng and reducing risk for potential fractures in endodontically treated teeth. J. Endod. 2010, 36, 609-617. [CrossRef] [PubMed]

4. Tamse, A.; Zilburg, I.; Halpern, J. Vertical root fractures in adjacent maxillary premolars: An endodontic-prosthetic perplexity. Int. Endod. J. 1998, 31, 127-132. [CrossRef] [PubMed]

5. Reeh, E.S.; Messer, H.H.; Douglas, W.H. Reduction in tooth stiffness as a result of endodontic and restorative procedures. J. Endo. 1989, 15, 512-516. [CrossRef]

6. Uzunoglu-Özyürek, E.; Eren, S.K.; Eraslan, O.; Belli, S. Critical evaluation of fracture of strength testing for endodontically treated teeth: A finite element analysis study. Restor. Dent. Endod. 2019, 44, e15. [CrossRef]

7. Taha, N.A.; Palamara, J.E.; Messer, H.H. Fracture strength and fracture patterns of root filled teeth restored with direct resin restorations. J. Dent. 2011, 39, 527-535. [CrossRef] [PubMed]

8. Rees, J.S. An investigation into the importance of the periodontal ligament and alveolar bone as supporting structures in finite element studies. J. Oral. Rehabil. 2001, 28, 425-432. [CrossRef]

9. Soares, C.J.; Pizi, E.C.G.; Fonseca, R.B.; Martins, L.R.M. Influence of root embedment material and periodontal ligament simulation on fracture resistance tests. Braz. Oral Res. 2005, 19, 11-16. [CrossRef]

10. Rossomando, K.J.; Wendt, S.L. Thermocycling and dwell times in microleakage evaluation for bonded restorations. Dent. Mater. 1995, 11, 47-51. [CrossRef]

11. Page, M.J.; McKenzie, J.E.; Bossuyt, P.M.; Boutron, I.; Hoffmann, T.C.; Mulrow, C.D.; Shamseer, L.; Tetzlaff, J.M.; Akl, E.A.; Brennan, S.E.; et al. The PRISMA 2020 statement: An updated guideline for reporting systematic reviews. BMJ 2021, $372, \mathrm{n} 71$. [CrossRef] [PubMed]

12. Gokturk, H.; Karaarslan, E.Ş.; Tekin, E.; Hologlu, B.; Sarikaya, I. The effect of the different restorations on fracture resistance of root-filled premolars. BMC. Oral Health 2018, 18, 196. [CrossRef]

13. Oz, F.; Attar, N.U.R.A.Y.; Sungur, D. The influence of restorative material and glass fiber posts on fracture strength of endodontically treated premolars after extensive structure loss. Niger J. Clin. Pract. 2019, 22, 782-789. [CrossRef]

14. Eapen, A.M.; Amirtharaj, L.V.; Sanjeev, K.; Mahalaxmi, S. Fracture Resistance of Endodontically Treated Teeth Restored with 2 Different Fiber-reinforced Composite and 2 Conventional Composite Resin Core Buildup Materials: An in Vitro Study. J. Endod. 2017, 43, 1499-1504. [CrossRef]

15. Zogheib, C.; Sfeir, G.; Plotino, G.; Deus, G.; Daou, M.; Khalil, I. Impact of Minimal Root Canal Taper on the Fracture Resistance of Endodontically Treated Bicuspids. J. Int. Soc. Prev. Community Dent. 2018, 8, 179-183. [CrossRef]

16. Hshad, M.E.; Dalkilic, E.E.; Ozturk, G.C.; Dogruer, I.; Koray, F. Influence of Different Restoration Techniques on Fracture Resistance of Root-filled Teeth: In Vitro Investigation. Oper. Dent. 2018, 43, 162-169. [CrossRef]

17. Soares, P.V.; Santos-Filho, P.C.F.; Queiroz, E.C.; Araújo, T.C.; Campos, R.E.; Araújo, C.A.; Soares, C.J. Fracture resistance and stress distribution in endodontically treated maxillary premolars restored with composite resin. J. Prosthodont. 2008, 17, 114-119. [CrossRef]

18. Sengun, A.; Cobankara, F.K.; Orucoglu, H. Effect of a new restoration technique on fracture resistance of endodontically treated teeth. Dent. Traumatol. 2008, 24, 214-219. [CrossRef] [PubMed]

19. Mondelli, J.; Sene, F.; Pereira Ramos, R.; Benetti, A.R. Tooth structure and fracture strength of cavities. Braz. Dent. J. 2007, 18, 134-138. [CrossRef] [PubMed]

20. Angol, R.J.; Ghiggi, P.C.; Paranhos, M.P.; Borges, G.A.; Burnett, L.H., Jr.; Spohr, A.M. Influence of resin cements on cuspal deflection and fracture load of endodontically-treated teeth restored with composite inlays. Acta. Odontol. Scand. 2013, 71, 664-670.

21. Taha, N.A.; Maghaireh, G.A.; Bagheri, R.; Holy, A.A. Fracture strength of root filled premolar teeth restored with silorane and methacrylate-based resin composite. J. Dent. 2015, 43, 735-741. [CrossRef]

22. Spicciarelli, V.; Marruganti, C.; Di Matteo, C.; Martignoni, M.; Ounsi, H.; Doldo, T.; Grandini, S. Influence of single post, oval, and multi-post restorative techniques and amount of residual tooth substance on fracture strength of endodontically treated maxillary premolars. J. Oral. Sci. 2020, 63, 70-74. [CrossRef]

23. Santos, M.J.M.C.; Bezerra, R.B. Fracture resistance of maxillary premolars restored with direct and indirect adhesive techniques: Randomized Controlled Trial. J. Can. Dent. Assoc. 2005, 71, 585.

24. Plotino, G.; Grande, N.M.; Isufi, A.; Ioppolo, P.; Pedullà, E.; Bedini, R.; Gambarini, G.; Testarelli, L. Fracture Strength of Endodontically Treated Teeth with Different Access Cavity Designs. J. Endod. 2017, 43, 995-1000. [CrossRef] [PubMed]

25. Harsha, M.S.; Praffulla, M.; Babu, M.R.; Leneena, G.; Krishna, T.S.; Divya, G. The Effect of Cavity Design on Fracture Resistance and Failure Pattern in Monolithic Zirconia Partial Coverage Restorations-an in vitro study. J. Clin. Diagn. Res. 2017, 11, ZC45. [CrossRef] 
26. Monga, P.; Sharma, V.; Kumar, S. Comparison of fracture resistance of endodontically treated teeth using different coronal restorative materials: An in vitro study. J. Conserv. Dent. 2009, 12, 154-159. [PubMed]

27. Kemaloglu, H.; Kaval, M.E.; Turkun, M.; Kurt, S.M. Effect of novel restoration techniques on the fracture resistance of teeth treated endodontically: An in vitro study. Dent. Mater. J. 2015, 34, 618-622. [CrossRef] [PubMed]

28. Mashyakhy, M.; Jabali, A.; Karale, R.; Parthiban, G.; Sajeev, S.; Bhandi, S. Comparative evaluation of fracture toughness and marginal adaptation of two restorative materials in non-endodontically and endodontically treated teeth: An in vitro study. Niger. J. Clin. Pract. 2020, 23, 349-354. [PubMed]

29. de V Habekost, L.; Camacho, G.B.; Pinto, M.B.; Demarco, F.F. Fracture resistance of premolars restored with partial ceramic restorations and submitted to two different loading stresses. Oper. Dent. 2006, 31, 204-211. [CrossRef]

30. Soares, P.V.; Santos-Filho, P.C.; Martins, L.R.; Soares, C.J. Influence of restorative technique on the biomechanical behavior of endodontically treated maxillary premolars. Part I: Fracture resistance and fracture mode. J. Prosthet. Dent. 2008, 99, 30-37. [CrossRef]

31. Desai, P.D.; Das, U.K. Comparison of fracture resistance of teeth restored with ceramic inlay and resin composite: An in vitro study. Indian J. Dent. Res. 2011, 22, 877. [CrossRef]

32. Karzoun, W.; Abdulkarim, A.; Samran, A.; Kern, M. Fracture strength of endodontically treated maxillary premolars supported by a horizontal glass fiber post: An in vitro study. J. Endod. 2015, 41, 907-912. [CrossRef] [PubMed]

33. Taha, N.A.; Palamara, J.E.; Messer, H.H. Fracture strength and fracture patterns of root-filled teeth restored with direct resin composite restorations under static and fatigue loading. Oper. Dent. 2014, 39, 181-188. [CrossRef] [PubMed]

34. Skupien, J.A.; Kreulen, C.; Opdam, N.; Bronkhorst, E.; Pereira-Cenci, T.; Huysmans, M.C. Effect of Remaining Cavity Wall, Cervical Dentin, and Post on Fracture Resistance of Endodontically Treated, Composite Restored Premolars. Int. J. Prostodont. 2016, 29, 154-156. [CrossRef]

35. Shahrbaf, S.; Mirzakiuchaki, B.; Oskoui, S.S.; Kahnamoui, M.A. The effect of marginal ridge thickness on the fracture resistance of endodontically-treated, composite restored maxillary premolars. Open Dent. 2007, 32, 285-290. [CrossRef]

36. Gürel, M.A.; Helvacioğlu Kivanç, B.; Ekıc1, A.; Alaçam, T. Fracture Resistance of Premolars Restored Either with Short Fiber or Polyethylene Woven Fiber-Reinforced Composite. J. Esthet. Restor. Dent. 2016, 28, 412-418. [CrossRef]

37. Jantarat, J.; Palamara, J.E.; Messer, H.H. An investigation of cuspal deformation and delayed recovery after occlusal loading. J. Dent. 2001, 29, 363-370. [CrossRef]

38. Ausiello, P.; Apicella, A.; Davidson, C.L. Effect of adhesive layer properties on stress distribution in composite restoration-a 3D finite element analysis. Dent. Mater. 2002, 18, 295-303. [CrossRef]

39. Yang, H.S.; Lang, L.A.; Molina, A.; Felton, D.A. The effects of dowel design and load direction on dowel-and-core restoration. J. Prosthet. Dent. 2001, 85, 558-567. [CrossRef]

40. Sabery, E.A.; Pirhaji, A.; Zabetiyan, F. Effect of Endodontic Access Cavity Design and Thermocycling on Fracture strengt of Endodontically treated teeth. Clinical, Cosmetic and Investigational Dentistry. Clin. Cosmet. 2020, 12, 149-156. 